\title{
Measures to improve knowledge and self-care among patients with COPD: a UK general practice audit
}

\author{
Agnelo Fernandes ${ }^{a}$, Susan Pache ${ }^{a}$, William Bird ${ }^{b}$, Clare Bryden $^{b, *}$
}

\author{
a The Parchmore Partnership, London, UK \\ ${ }^{\mathrm{b}}$ Met Office, FitzRoy Road, Exeter, EX1 3PB, UK
}

Received 12 January 2006; accepted 10 July 2006

KEYWORDS

COPD;

Patient education;

Self-care

\begin{abstract}
Summary The Parchmore Partnership, Lonc sn, audited 11 evidence-based criteria relating to patient knowledge and C (PL nc r jicity during December 2004 to March 2005 using questionna ires inc pri.cl ce recoids. 32 patients wi th moderate to severe

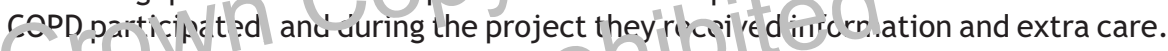
Patie t krowledge and clinical indiracors il o vec signiticant improvements.

Crown Copyright (c) ? 200 ? ib ished ty Elsevier Ltd on behalf of General Practice Airwavs Gailu. All rist ts ieserved.
\end{abstract}

\section{Introduction}

Various criteria concerning the management of Chronic Obstructive Pulmonary Disease (COPD) are included in the Quality and Outcomes Framework (QOF) of the UK general practice contract, which sets out a system of financial incentives for improving quality of care [1]. The National Institute for Clinical Excellence (NICE) has published guidelines for COPD care [2].

In the winter of 2004/2005, the Met Office (the UK's national meteorological service) ran a trial of COPD health forecasting with anticipatory care [3]. Participation in the trial prompted The Parchmore Partnership to conduct an audit, aiming

\footnotetext{
* Corresponding author. Tel.: +44 (0) 1392886607 ; fax: +44 (0) 1392885681 .

E-mail address: clare.bryden@metoffice.gov.uk (C. Bryden).
}

to assess and improve the knowledge of patients with moderate to severe COPD with regards to self-care, and the key clinical indicators of good practice for COPD care.

\section{Methods}

Patients with COPD were identified from the practice electronic disease register, and subdivided by spirometry-based severity into three categories: mild (Read Code H36); moderate (H37); and severe (H38) [2].

The care of patients with moderate to severe COPD was audited with regards to eleven evidencebased criteria relating to COPD morbidity and corresponding targets (Table 1 ) $[1,2,4,5]$. Four criteria and targets related to the QOF. Seven criteria related to the Met Office project, setting 
Table 1 Audit criteria, standards and outcomes

\begin{tabular}{|c|c|c|c|c|}
\hline Patients should. . & Target & Dec04a & Mar05a & Increase Dec04-Mar05 \\
\hline $\begin{array}{l}\text { 1. Have had a pneumonia or flu vaccination this } \\
\text { year }[1,2]\end{array}$ & $85 \%{ }^{b}$ & $87 \%$ & $96 \%$ & $9 \%(p<0.05)$ \\
\hline 2. Understand how to use their inhalers $[1,2]$ & $90 \%$ b & $81 \%$ & $97 \%$ & $16 \%(p<0.001)$ \\
\hline $\begin{array}{l}\text { 3. Know what to do if they develop a cold or their } \\
\text { breathing worsens }[2,4]\end{array}$ & $90 \%$ & $84 \%$ & $98 \%$ & $14 \%(p<0.001)$ \\
\hline $\begin{array}{l}\text { 4. Have the right telephone numbers to call if } \\
\text { they start to feel ill [4] }\end{array}$ & $90 \%$ & $87 \%$ & $97 \%$ & $10 \%(p<0.01)$ \\
\hline $\begin{array}{l}\text { 5. Have discussed their level of exercise with their } \\
\text { nurse/GP [2] }\end{array}$ & $70 \%$ & $48 \%$ & $91 \%$ & $43 \%(p<0.001)$ \\
\hline $\begin{array}{l}\text { 6. Wrap up to keep warm when outside in cold } \\
\text { weather [5] }\end{array}$ & $90 \%$ & $89 \%$ & $98 \%$ & $9 \%(p<0.01)$ \\
\hline $\begin{array}{l}\text { 7. Have a thermometer to keep their living-room } \\
\text { at } \geq 21^{\circ} \mathrm{C} \text { and bedroom at } \geq 18^{\circ} \mathrm{C}[5]\end{array}$ & $70 \%$ & $47 \%$ & $92 \%$ & $45 \%(p<0.001)$ \\
\hline $\begin{array}{l}\text { 8. Keep spare antibiotics/steroids at home in case } \\
\text { their breathing worsens [2] }\end{array}$ & $90 \%$ & $50 \%$ & $93 \%$ & $43 \%(p<0.001)$ \\
\hline $\begin{array}{l}\text { 9. Have had a review of their condition with } \\
\text { spirometry }[1,2]\end{array}$ & $90 \%{ }^{\mathrm{b}}$ & $67 \%$ & $92 \%$ & $25 \%(p<0.001)$ \\
\hline $\begin{array}{l}\text { 10. Have been given smoking cessation advice if } \\
\text { they smoked }[1,2]\end{array}$ & $90 \%{ }^{\mathrm{b}}$ & $81 \%$ & $96 \%$ & $15 \%(p<0.001)$ \\
\hline 11. Have given up smoking $[1,2]$ & $90 \%$ & $82 \%$ & $88 \%$ & $6 \%$ (not sig) \\
\hline
\end{tabular}

realistic targets given the practice socio-economic profile.

The Met Office provided forecasts of the risk of COPD hospital admission during rioven () e 2 204 to March 2005. Patients with moto: aie to severe COPD were written to on 21 December 2004 seekirgt $t$ i consent to participate, i.e giving the r cuntact details to NHS Direct a Zs-hour nurse-led advice service), receiving subsequent telephone contact, and completing questionnaires.

Participating patients received extra care during January-February 2005. This constituted:

- NHS Direct nurses making three telephone calls when elevated risk was forecast

- information packs about COPD and knowledge for self-care were sent by request from NHS Direct

- systems were established to fast-track COPD patients who contacted the practice

- the practice multidisciplinary team utilised opportunistic patient contacts, review of hospital letters and call/recall

Audit data were collected in two cycles. Data for the four QOF-related criteria were obtained from the practice computer system in December 2004 and March 2005. Data for the remaining seven criteria were obtained through a questionnaire in the initial letter to patients, and questionnaires were completed by NHS Direct nurses during patient contacts in January and February.
The audit $x$ t:omes corresponding to the 11 criteria were coriverted into percentage rates, and canges between the tw? c) cles were tested for statistical si if cance using ine chi-squared test.

\section{Results}

In this practice of 12,566 patients, 98 patients $(0.8 \%)$ were identified with COPD. 44 out of the 98 patients had moderate to severe COPD. 34 out of these 44 patients responded to the letter of December 2004. 32 patients gave written consent to participate.

In December 2004, one audit target - influenza vaccination - was met, but several targets were missed by substantial margins (see Table 1). During the audit, standards for the 11 criteria improved ( $p<0.05$ except for smoking cessation), in particular those criteria concerning exercise, indoor temperature and patients having a spare supply of antibiotics/steroids. By March 2005, ten targets were met, but the criterion regarding smoking cessation was not.

Following calls by NHS Direct nurses, six patients phoned the surgery to request antibiotics or steroids, and two patients arranged spirometry. Many patients requested more information about COPD, especially with regards to symptoms and exercise, and NHS Direct nurses provided them with information packs. 


\section{Discussion}

The audit aims - to improve key clinical indicators and the patients' knowledge of their condition and measures for self-care - were met.

The patients demonstrated a previously unmet need for basic information about COPD. Patient feedback suggests that the information provided by the NHS Direct nurses was helpful, particularly when they had continued contact with the same nurse.

The practice's view is that information and care can be successfully provided by telephone, and that the use of an external agency to contact patients enhanced the efficiency and consistency of care by the multidisciplinary practice team.

The Met Office project prompted the provision of extra care through education and telephone contacts. The audit did not investigate whether the timing of patient contact (when elevated risk was forecast) was important.

Audit follow-up will include training lay Health Care Assistants to run smoking cessation clinics with guidance and to undertake spirometry and to disseminate information about COPD, thereby freeing practice nurses to concentrate on the clinical management of COPD patients.

\section{Acknowledgements}

Blanca Fernandez, Health Information Manager, NHS Direct South London.

All patients and NHS Direct nurses who participated in the project.

\section{References}

[1] Investing in general practice. The new general medical services contract. London: British Medical Association. 2003.

[2] National Collaborating Centre for Chronic Conditions. Chronic Obstructive Pulmonary Disease. National clinical guideline on management of chronic obstructive pulmonary disease in adults in primary and secondary care. Thorax 2004;59 Supp1:i1-i232.

[3] http://www.metoffice.gov.uk/health/copd_forecasting.html (Accessed 3.3.06)

[4] Seemungal TA, Donaldson GC, Bhowmik A, Jeffries DJ, Wedzicha JA. Time course and recovery of exacerbations in patients with chronic obstructive pulmonary disease. Am J Respir Crit Care Med 2000;161:1608-13.

[5] Donaldson GC, Seemungal T, Jeffries DJ, Wedzicha JA. Effect of temperature on lung function and symptoms in chronic obstructive pulmonary disease. Eur Respir J 1999;13: 844-9.

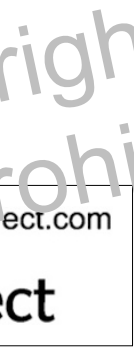

